\title{
Random non-fasting C-peptide testing can identify patients with insulin-treated type 2 diabetes at high risk of hypoglycaemia
}

\author{
Suzy V. Hope ${ }^{1,2} \cdot$ Bridget A. Knight $^{1} \cdot$ Beverley M. Shields $^{1} \cdot$ Anita V. Hill $^{1}$. \\ Pratik Choudhary $^{3}$ - W. David Strain ${ }^{2}$ - Timothy J. McDonald ${ }^{1} \cdot$ Angus G. Jones ${ }^{1}$
}

Received: 24 March 2017 / Accepted: 27 July 2017 / Published online: 5 October 2017

(C) The Author(s) 2017. This article is an open access publication

\begin{abstract}
Aims/hypothesis The aim of this study was to determine whether random non-fasting C-peptide ( $\mathrm{rCP}$ ) measurement can be used to assess hypoglycaemia risk in insulin-treated type 2 diabetes.

Methods We compared continuous glucose monitoringassessed SD of blood glucose and hypoglycaemia duration in 17 patients with insulin-treated type 2 diabetes and severe insulin deficiency $(\mathrm{rCP}<200 \mathrm{pmol} / \mathrm{l})$ and 17 matched insulintreated control patients with type 2 diabetes but who had preserved endogenous insulin $(\mathrm{rCP}>600 \mathrm{pmol} / \mathrm{l})$. We then assessed the relationship between $\mathrm{rCP}$ and questionnairebased measures of hypoglycaemia in 256 patients with insulin-treated type 2 diabetes and a comparison group of 209 individuals with type 1 diabetes.

Results Continuous glucose monitoring (CGM)-assessed glucose variability and hypoglycaemia was greater in individuals with $\mathrm{rCP}<200 \mathrm{pmol} / 1$ despite similar mean glucose. In those
\end{abstract}

Electronic supplementary material The online version of this article (https://doi.org/10.1007/s00125-017-4449-2) contains peer-reviewed but unedited supplementary material, which is available to authorised users.

Suzy V. Hope

S.V.Hope@exeter.ac.uk

Angus G. Jones

angus.jones@exeter.ac.uk

1 NIHR Exeter Clinical Research Facility, University of Exeter Medical School and Royal Devon and Exeter NHS Foundation Trust, Barrack Road, Exeter EX2 5DW, UK

2 Diabetes and Vascular Medicine, University of Exeter Medical School and Royal Devon and Exeter NHS Foundation Trust, Exeter, UK

3 Department of Diabetes, King's College London, London, UK with low vs high C-peptide, SD of glucose was $4.2(95 \% \mathrm{CI}$ $3.7,4.6)$ vs $3.0(2.6,3.4) \mathrm{mmol} / \mathrm{l}(p<0.001)$. In the low-Cpeptide vs high-C-peptide group, the proportion of individuals experiencing sustained hypoglycaemia $\leq 4 \mathrm{mmol} / 1$ was $94 \%$ vs $41 \%$ ( $p<0.001$ ), the mean rate of hypoglycaemia was 5.5 $(4.4,6.7)$ vs $2.1(1.4,2.9)$ episodes per person per week $(p=0.004)$ and the mean duration was $630(619,643)$ vs $223(216,230)$ min per person per week $(p=0.01)$. Hypoglycaemia $\leq 3 \mathrm{mmol} / \mathrm{l}$ was infrequent in individuals with preserved C-peptide $(1.8[1.2,2.6]$ episodes per person per week vs $0.4[0.1,0.8]$ episodes per person per week for low vs high C-peptide, $p=0.04$ ) and only occurred at night. In a population-based cohort with insulin-treated type 2 diabetes, self-reported hypoglycaemia was twice as frequent in those with $\mathrm{rCP}<200 \mathrm{pmol} / 1$ (OR 2.0, $p<0.001$ ) and the rate of episodes resulting in loss of consciousness or seizure was five times higher (OR 5.0, $p=0.001$ ). The relationship between self-reported hypoglycaemia and C-peptide was similar in individuals with type 1 and type 2 diabetes.

Conclusions/interpretation Low $\mathrm{rCP}$ is associated with increased glucose variability and hypoglycaemia in patients with insulin-treated type 2 diabetes and represents a practical, stable and inexpensive biomarker for assessment of hypoglycaemia risk.

Keywords Continuous glucose monitoring · C-peptide . Diabetes $\cdot$ Hypoglycaemia $\cdot$ Insulin $\cdot$ Type 2 diabetes
Abbreviations
CGM Continuous glucose monitoring
DARE Diabetes Alliance for Research in England
IA2 Islet antigen 2
LBGI Low blood glucose index
MAGE Mean amplitude of glycaemic excursions 
rCP Random non-fasting C-peptide

SMBG Self-monitoring of blood glucose

\section{Introduction}

Individuals with type 1 diabetes usually develop severe endogenous insulin deficiency, which results in high glucose variability and hypoglycaemia risk [1-4]. Treatment guidelines for type 1 diabetes, therefore, incorporate early intensive strategies to minimise hypoglycaemia, including multiple daily insulin injections, carbohydrate counting and insulin pumps [5].

Endogenous insulin deficiency is best assessed using Cpeptide [6]. In the DCCT study, intensively treated participants with type 1 diabetes with mixed meal teststimulated C-peptide $<200 \mathrm{pmol} / \mathrm{l}$ had three times as many episodes of severe hypoglycaemia than other participants, despite having higher $\mathrm{HbA}_{1 \mathrm{c}}[2,3]$. This threshold of $200 \mathrm{pmol} / \mathrm{l}$ is commonly described as identifying absolute insulin deficiency, although modern assays can measure below this range $[7,8]$ and a relationship between hypoglycaemia and lower levels of C-peptide has been described $[9,10]$.

We have recently demonstrated that a random non-fasting plasma C-peptide ( $\mathrm{rCP}$ ) sample is a sensitive and specific measure for mixed meal tolerance test-defined absolute insulin deficiency (stimulated C-peptide $<200 \mathrm{pmol} / \mathrm{l}$ ), with the same C-peptide threshold having a sensitivity and specificity of $100 \%$ and $93 \%$, respectively [11]. As Cpeptide is stable in whole blood collected into EDTA for $>24 \mathrm{~h}$ [12], this means severe insulin deficiency can be identified from a routine non-fasting blood sample when a patient is seen in the clinic.

Severe insulin deficiency can occur in insulin-treated patients who have clinical features consistent with type 2 diabetes, but the deficiency is usually not recognised [13-16]. This is likely to be an increasing problem as obesity rates increase, making clinical classification more difficult. We hypothesise that individuals with severe insulin deficiency will have high glycaemic variability and high hypoglycaemia risk whatever the underlying diabetes aetiology or classification. Identifying individuals with apparent type 2 diabetes who have developed severe insulin deficiency could assist appropriate management, including consideration of the intensive strategies to minimise hypoglycaemia traditionally used in type 1 diabetes.

We therefore aimed to determine whether $\mathrm{rCP}$ measurement can be used to assess risk of hypoglycaemia in insulin-treated patients with a clinical diagnosis of type 2 diabetes.

\section{Methods}

We assessed whether severe insulin deficiency defined by a low $\mathrm{rCP}$ is associated with high rates of hypoglycaemia and glucose variability, as assessed by continuous glucose monitoring (CGM), in patients with insulin-treated type 2 diabetes. We replicated our findings using questionnairebased assessment of hypoglycaemia in a large population cohort of patients with insulin-treated type 2 diabetes and a cohort with type 1 diabetes as a comparison group.

Ethics approval Ethics approvals were obtained from the National Research Ethics Service (NRES) Committee South West (UK).

\section{CGM assessment of glucose variability and hypoglycaemia in insulin-treated patients with type 2 diabetes with low or preserved endogenous insulin secretion}

Participants We recruited 17 insulin-treated individuals with a clinical diagnosis of type 2 diabetes and severe insulin deficiency and a control group of 17 matched individuals with relatively preserved endogenous insulin secretion. All participants were diagnosed aged 35 years or older, treated without insulin for at least 2 years beyond diagnosis and had an eGFR $>30 \mathrm{ml} \mathrm{min}^{-1}(1.73 \mathrm{~m})^{-2}$. Participants were recruited based on known C-peptide result and clinical characteristics in the Diabetes Alliance for Research in England (DARE) study, http://www.diabetesgenes.org/content/diabetesalliance-research-england-dare-previously-known-exeterresearch-alliance-extra-stud, an unselected population-based study of adults with diabetes in Devon (UK), recruited predominantly through primary care. The 17 participants with severe insulin deficiency $(\mathrm{rCP}<200 \mathrm{pmol} / \mathrm{l})$ were individually matched by sex and $\mathrm{HbA}_{1 \mathrm{c}}( \pm 10 \mathrm{mmol} / \mathrm{l})$ with a control participant who had preserved endogenous insulin secretion ( $\mathrm{rCP}>600 \mathrm{pmol} / \mathrm{l})$. C-peptide categories were chosen based on previously reported thresholds for severe insulin deficiency/high hypoglycaemia risk in type 1 diabetes $(<200 \mathrm{pmol} / \mathrm{l})$ and for type 2 diabetes/insulin requirement $(>600 \mathrm{pmol} / \mathrm{l})[6]$.

Baseline visit Participants attended non-fasting within $5 \mathrm{~h}$ of a meal, without restriction on snacks or other intakes. Following informed consent, baseline characteristics were recorded and blood taken for repeat $\mathrm{rCP}, \mathrm{HbA}_{1 \mathrm{c}}$ and islet autoantibody status (GAD/islet antigen 2 [IA2]). Clarke's Hypoglycaemia Questionnaire [17] was completed by all participants.

CGM At the baseline visit, participants commenced at least three consecutive days' CGM (iPro2 Professional; Medtronic, 
Watford, UK). For calibration purposes, participants were asked to record four self-monitoring blood glucose tests daily over the CGM period.

The following criteria were required for CGM data to be included in analysis [18]: three or more self-monitoring of blood glucose (SMBG) calibrations in $24 \mathrm{~h}$; no missing data points; correlation between SMBG and iPro2 readings $>0.77$ in $24 \mathrm{~h}$; mean difference between SMBG and iPro2 readings for each $24 \mathrm{~h}(\mathrm{MAD} \%)<28 \%$ and a minimum of $24 \mathrm{~h}$ data meeting these criteria.

CGM analysis The mean glucose, SD of glucose measurements, mean amplitude of glycaemic excursions (MAGE) and low blood glucose index (LBGI) were analysed for each individual using EasyGV online software [19], N. Hill, University of Oxford, Oxford, UK; https://www.phc.ox. ac.uk/research/technology-outputs/easygv.

An episode of hypoglycaemia was defined as $\geq 20 \mathrm{~min}$ at or below the interstitial glucose level of 4,3 or $2.2 \mathrm{mmol} / \mathrm{l}$, and only complete once readings had been above the threshold for $>20$ min [19]. Results were converted to rates of hypoglycaemia and duration of hypoglycaemia per person per week, and by day (08:00-00:00 hours) and night (00:00-08:00 hours).

Laboratory analyses C-peptide was analysed using the automated Roche diagnostics (Manheim, Germany) E170 immuno-analyser (limit of detection $3.3 \mathrm{pmol} / \mathrm{l}$, inter- and intra-assay coefficients of variation $<4.5 \%$ and $<3.3 \%$, respectively) in the Blood Sciences department, Royal Devon and Exeter Hospital.

GAD65 and IA2 autoantibodies were assessed using the RSR Elisa kits (Cardiff, UK) on a Dynex DS2 automated Elisa System (Dynex Technologies, Worthing, UK). Cut-offs used were based on the 97.5th centile for 1600 adults without diabetes; the reference positive value was $>11 \mathrm{U} / \mathrm{ml}$ for GAD65 and $>15 \mathrm{U} / \mathrm{ml}$ for IA2.

Statistical analysis Differences in continuous measures of glucose variability and hypoglycaemia and baseline characteristics between low- and high-C-peptide pairs were assessed using paired $t$ tests, as differences in paired data approximated normal distribution. For comparing proportions, $\chi^{2}$ tests were used.

To assess whether our findings were independent of insulin regime, a potential source of confounding [20,21], we performed an additional unpaired sensitivity analysis comparing measures of glucose variability and hypoglycaemia between C-peptide groups, with adjustment for use of prandial or mixed insulin using ANCOVA and (for rates) Poisson regression.
Assessment of the relationship between $\mathrm{rCP}$ and self-reported hypoglycaemia in patients with insulin-treated diabetes

Participants Four hundred and sixty-five (256 type 2 diabetes, 209 type 1 diabetes, reported clinician diagnosis) insulintreated patients in the DARE study (see above), were recruited by postal invitation (existing DARE cohort) or at DARE recruitment visit, of whom 27 also participated in our CGM cohort (above).

C-peptide assessment Non-fasting C-peptide was measured at participants' recruitment visit or, for participants previously recruited to the DARE study, with prior written informed consent, measured on residual plasma from routine nonfasting clinical laboratory analysis.

Hypoglycaemia questionnaires Participants completed a modified Clarke's Hypoglycaemia Questionnaire [17, 22] by post (existing DARE cohort) or at DARE recruitment visit. Hypoglycaemia awareness was assessed by calculating the Clarke score [17]: questions are each allocated a score of 0 (aware) or 1 (reduced awareness), and the score for the seven questions added together. A score of 4 or more is classed as 'reduced awareness', as previously reported [17].

Clarke's Hypoglycaemia question 5 (frequency of episodes in the last month where blood glucose $<3.5 \mathrm{mmol} / \mathrm{l}$, with symptoms) and question 6 (episodes where blood glucose $<3.5 \mathrm{mmol} / \mathrm{l}$, without symptoms) categorise self-reported frequency into groups. Thus, for analysis we assigned an estimated frequency per answer for an approximation of frequency in the last month: 1-3 episodes in the last month became 2 ; one episode per week became $1 \times 4=4$; two or three episodes per week became $2.5 \times 4=10$; four or five episodes per week became $4.5 \times 4=18$ and almost daily was estimated at 25 episodes per month.

Statistical analysis Rates of self-reported hypoglycaemia were assumed to follow a Poisson distribution, so data are presented as incidence rates and incidence rate ratios. We compared rates of self-reported hypoglycaemia $<3.5 \mathrm{mmol} / 1$ (Clarke questions 5 and 6, events per person per month) in individuals with a clinical diagnosis of type 2 diabetes with and without $\mathrm{rCP}<200 \mathrm{pmol} / \mathrm{l}$ using the $z$ test. CIs around rates were calculated using the Poisson distribution. We compared the proportion of participants reporting at least one episode of hypoglycaemia in Clarke questions 3-6, and the proportion with calculated reduced hypoglycaemia awareness (Clarke score $\geq 4$ ), using the $\chi^{2}$ test.

To assess whether differences between groups were due to confounding by differences in clinical features associated with hypoglycaemia and insulin type [21], we assessed the OR (proportions, logistic regression) and rate ratio (questions 5 
and 6 rate, Poisson regression) for the above outcomes with and without adjustment for age, sex, $\mathrm{HbA}_{1 \mathrm{c}}$ and use of prandial or mixed insulin (vs intermediate- or long-acting insulin only). These covariates were associated with selfreported hypoglycaemia rate in univariate analysis $(p<0.002$ for all).

We repeated this analysis in individuals with type 1 diabetes.

To ensure results did not reflect poor accuracy of reported clinical diagnosis, we also repeated analysis in subgroups defined by the following restrictive criteria for type 1 and 2 diabetes: (1) type 1 diabetes-clinician diagnosis of type 1 diabetes, diabetes onset before age 35 years and insulin treatment within 6 months of diagnosis and (2) type 2 diabetes-clinician diagnosis of type 2 diabetes, diagnosis $\geq$ age 35 years and time to insulin $\geq 2$ years.

\section{Results}

\section{Assessment of glucose variability and hypoglycaemia in insulin-treated patients with type 2 diabetes with low or preserved endogenous insulin secretion}

Participant characteristics and data quality Participant characteristics are shown in Table 1. Mean CGM glucose (10.2 vs $9.9 \mathrm{mmol} / 1, p=0.5), \mathrm{HbA}_{1 \mathrm{c}}$, age, duration of diabetes and BMI were similar when comparing the low- and high-Cpeptide groups. However, participants with severe insulin deficiency had progressed more rapidly to insulin treatment, received higher insulin doses and were more likely to receive basal bolus insulin therapy and have positive islet cell autoantibodies.
The mean duration of CGM recording meeting inclusion criteria for analysis was 4.1 (range 1-6.2) days; this was similar between the two groups (4.3 [range 1-6.2] vs 3.9 [1.3-6] days in the low- vs high-C-peptide group, respectively, $p=0.34$ ).

SD of glucose readings on CGM was higher in the low-Cpeptide group Glucose variability was greater in the low-Cpeptide group: SD of glucose measurements $4.15 \mathrm{mmol} / 1$ (95\% CI 3.67, 4.64) vs $3.01 \mathrm{mmol} / \mathrm{l}(2.65,3.38), p<0.001$. MAGE did not differ between groups $(7.05 \mathrm{mmol} / \mathrm{l}[5.9,8.2]$ vs $6.03 \mathrm{mmol} / 1[4.8,7.3], p=0.1)$.

Hypoglycaemia is markedly more frequent in individuals with low C-peptide Of the 17 participants in the low-Cpeptide group, 16 (94\%) experienced at least one episode of hypoglycaemia on CGM ( $\geq 20 \mathrm{~min}, \leq 4 \mathrm{mmol} / \mathrm{l})$ compared with $7 / 17(41 \%)$ in the high-C-peptide group $(p<0.001)$ (Fig. 1a).

The rate of hypoglycaemia ( $\geq 20 \mathrm{~min}, \leq 4 \mathrm{mmol} / \mathrm{l}$ ) on CGM was higher in the low-C-peptide group than in the high-Cpeptide group $(5.5$ [95\% CI 4.4, 6.7] vs 2.1 [1.4, 2.9] episodes per person per week, $p=0.004$ ) (Fig. 1b). The total duration of hypoglycaemia was also higher in the low-C-peptide group (mean 630 [95\% CI 329, 931] vs 223 [14, 431] min per person per week, $p=0.01$ ) (Fig. 1c).

The frequency and total duration of episodes of more significant hypoglycaemia (interstitial glucose $\leq 3 \mathrm{mmol} / \mathrm{l}$ ) were also higher in the low-C-peptide group $(1.8[95 \% \mathrm{CI}$ $1.2,2.6]$ vs $0.4(0.1,0.8)$ episodes per person per week, $p=0.037 ; 199(47,352)$ vs $31[0,83]$ min per person per week, $p=0.049$ ) (Fig. 1b, c). All hypoglycaemia episodes
Table 1 Characteristics of the CGM-assessed hypoglycaemia cohort

\begin{tabular}{|c|c|c|c|}
\hline Characteristic & $\begin{array}{l}\text { C-peptide } \\
<200 \mathrm{pmol} / 1\end{array}$ & $\begin{array}{l}\text { C-peptide } \\
>600 \mathrm{pmol} / 1\end{array}$ & $p$ value \\
\hline No. of participants & 17 & 17 & - \\
\hline C-peptide, pmol/1 & $38.9(10.3,67.4)$ & $1238.3(906.5,1570.1)$ & - \\
\hline Mean glucose on CGM, mmol/1 & $10.2(9.1,11.3)$ & $9.9(8.6,11.1)$ & 0.50 \\
\hline $\mathrm{HbA}_{1 \mathrm{c}}, \mathrm{mmol} / \mathrm{mol}$ & $72.0(65.5,78.5)$ & $72.2(66.1,78.3)$ & 0.88 \\
\hline $\mathrm{HbA}_{1 \mathrm{c}}, \%$ & $8.7(8.1,9.3)$ & $8.7(8.4,9.3)$ & 0.88 \\
\hline Male sex, $n(\%)$ & $11(65)$ & $11(65)$ & - \\
\hline Age, years & $72.8(68.4,77.2)$ & $71.8(68.5,75.1)$ & 0.71 \\
\hline Diabetes duration, years & $24.5(19.0,30.0)$ & $19.8(16.8,22.9)$ & 0.13 \\
\hline BMI, $\mathrm{kg} / \mathrm{m}^{2}$ & $26.6(24.8,28.4)$ & $27.9(26.1,29.8)$ & 0.19 \\
\hline Time to insulin, months & $62(37,87)$ & $111(76,145)$ & 0.03 \\
\hline Total dose of insulin in $24 \mathrm{~h}, \mathrm{U} / \mathrm{kg}$ & $0.71(0.61,0.8)$ & $0.52(0.39,0.64)$ & 0.007 \\
\hline Use of prandial (basal bolus or mixed) insulin, $\%$ & 100 & 59 & 0.003 \\
\hline Proportion with $\geq$ one islet autoantibody, $\%$ & $59(28,100)$ & $6(2,33)$ & $<0.001$ \\
\hline
\end{tabular}

Values reported are mean $(95 \% \mathrm{CI})$ unless stated otherwise 

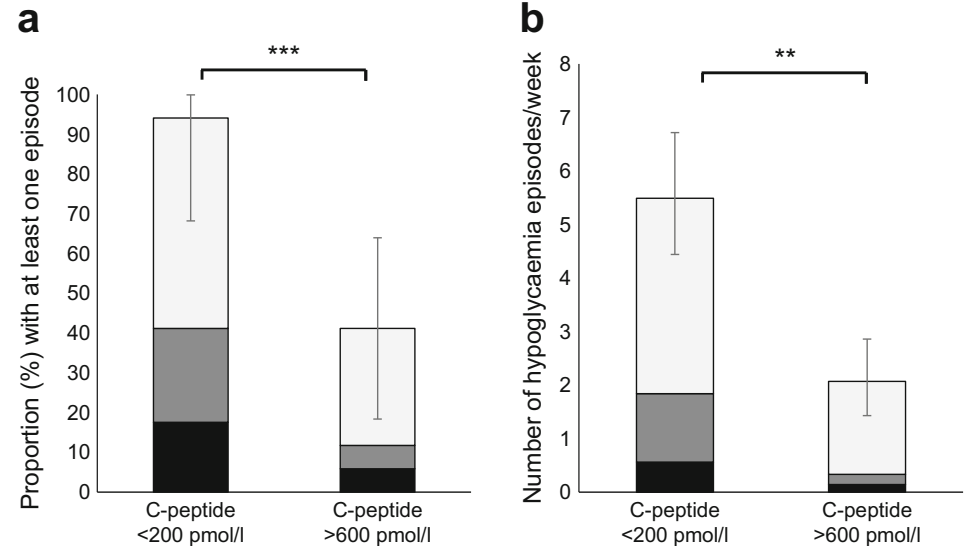

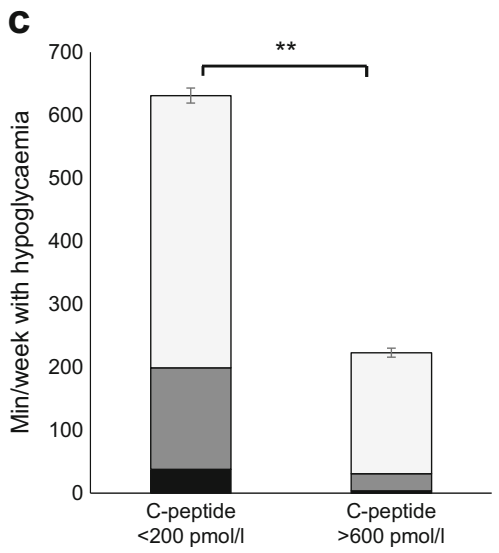

Fig. 1 Hypoglycaemia measured by CGM in individuals with $\mathrm{rCP}<200$ $\mathrm{pmol} / \mathrm{l}$ vs $>600 \mathrm{pmol} / \mathrm{l}$. Light grey section of bars, glucose threshold $\leq 4$ $\mathrm{mmol} / \mathrm{l}$; dark grey sections, $\leq 3 \mathrm{mmol} / \mathrm{l}$; black sections, $\leq 2.2 \mathrm{mmol} / \mathrm{l}$. Error bars represent 95\% CI. (a) Proportion of individuals with one or more hypoglycaemia episodes. (b) Rate of hypoglycaemia (no. of episodes per person per week). (c) Hypoglycaemia duration (minutes per person per week). $* * p \leq 0.01$ and $* * * p<0.001$ for $\mathrm{rCP}<200 \mathrm{pmol} / 1$ vs $>600 \mathrm{pmol} / \mathrm{l}$ below $3 \mathrm{mmol} / \mathrm{l}$ in the high-C-peptide group occurred at night (00:00-08:00 hours); in contrast 7/17 (41\%) of participants with low C-peptide experienced daytime hypoglycaemia $\leq 3 \mathrm{mmol} / \mathrm{l}$, with a mean rate of $1.3(0.8,2.0)$ episodes per person per week $(p=0.01)$. Rates of severe hypoglycaemia $\leq 2.2 \mathrm{mmol} / \mathrm{l}$ were low and did not significantly differ by $\mathrm{C}$ peptide status $(0.5[0.2,1]$ vs $0.1[0,0.4]$ episodes per person per week, $p=0.26$ ) (Fig. 1b). The LBGI was substantially higher in those with low C-peptide $(5.5[3.8,7.3]$ vs $1.9[0.8$, 3.0], $p<0.001)$.

Associations between C-peptide and hypoglycaemia were independent of insulin regimen In unpaired sensitivity analysis, the association between $\mathrm{C}$-peptide group and both glucose variability and hypoglycaemia was not substantially altered by adjustment for insulin regimen (see electronic supplementary material [ESM] Tables 1 and 2).

\section{Replication using self-reported hypoglycaemia in a population cohort}

Participant characteristics Participant characteristics for the hypoglycaemia questionnaire cohort are shown in Table 2 (type 2 diabetes) and ESM Table 3 (type 1 diabetes comparison cohort). Fourteen per cent of participants with a clinical diagnosis of insulin-treated type 2 diabetes had $\mathrm{rCP}<200 \mathrm{pmol} / \mathrm{l}$. These participants had similar age, diabetes duration and $\mathrm{HbA}_{1 \mathrm{c}}$ to participants with retained C-peptide but had lower BMI and time to insulin and greater use of prandial insulin.

Low C-peptide is associated with higher rates of selfreported hypoglycaemia in patients with insulin-treated type 2 diabetes In participants with insulin-treated type 2 diabetes, self-reported hypoglycaemia was approximately twice as common in those with $\mathrm{rCP}<200 \mathrm{pmol} / 1$ compared
Table 2 Characteristics of the questionnaire-assessed hypoglycaemia cohort with insulin-treated type 2 diabetes

\begin{tabular}{llll}
\hline Characteristics & $\begin{array}{l}\text { C-peptide } \\
<200 \text { pmol/1 }\end{array}$ & $\begin{array}{l}\text { C-peptide } \\
\geq 200 \mathrm{pmol} / 1\end{array}$ & $p$ value \\
\hline No. $(\%)$ of participants & $35(14)$ & $221(86)$ & - \\
$\mathrm{HbA}_{1 \mathrm{c}}, \mathrm{mmol} / \mathrm{mol}$ & $71.3(66.0,76.6)$ & $66.9(64.7,69.1)$ & 0.1 \\
$\mathrm{HbA}_{1 \mathrm{c}}, \%$ & $8.7(8.2,9.2)$ & $8.3(8.1,8.5)$ & 0.1 \\
Male sex, \% & $60(42,76)$ & $63(56,69)$ & 0.7 \\
Age, years & $68.2(64.4,72.0)$ & $66.0(64.7,73)$ & 0.2 \\
Duration of diabetes, years & $16.2(13.1,19.5)$ & $14.1(13.1,15.2)$ & 0.2 \\
BMI, kg/m & $28.2(26.4,30.0)$ & $32.2(31.5,33.0)$ & $<0.001$ \\
Time to insulin, months & $48.4(28.4,68.5)$ & $84.1(73.2,95.0)$ & 0.01 \\
Insulin dose in 24 h, U/kg & $0.73(0.58,0.87)$ & $0.63(0.56,0.69)$ & 0.3 \\
Use of prandial (basal bolus or mixed) insulin, \% & $84(64,95)$ & $44(36,51)$ & $<0.001$ \\
\hline
\end{tabular}

Values are reported as mean $(95 \% \mathrm{CI})$ unless stated otherwise 


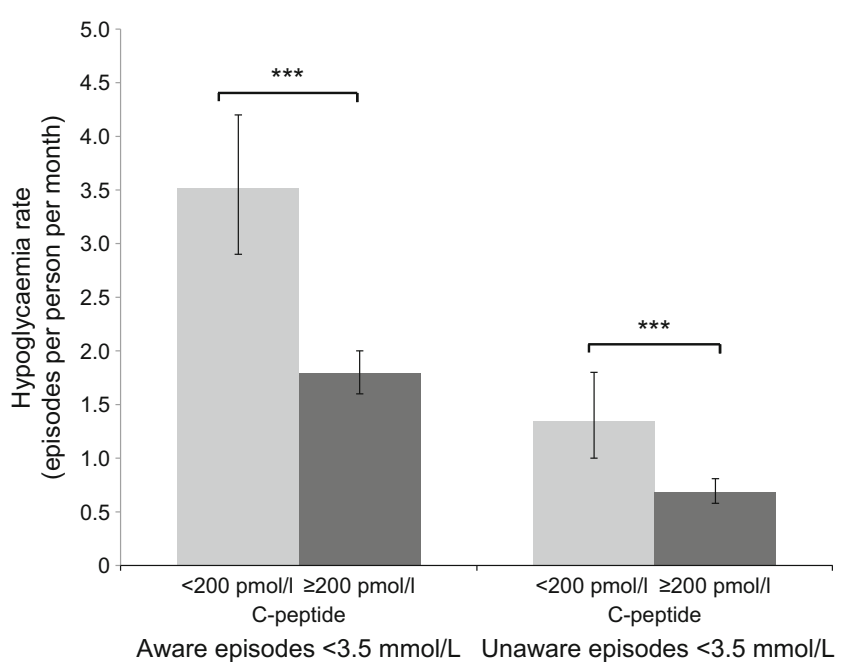

Fig. 2 Frequency of self-reported hypoglycaemia $(<3.5 \mathrm{mmol} / \mathrm{l})$ by Cpeptide status in patients with insulin-treated type 2 diabetes $(n=256)$. Light grey bars, $\mathrm{rCP}<200 \mathrm{pmol} / \mathrm{l}$; dark grey bars, $\mathrm{rCP} \geq 200 \mathrm{pmol} / \mathrm{l}$. Rates of aware and unaware episodes derived from Clarke questions 5 and 6, respectively. Error bars represent $95 \%$ CI. $* * * p<0.001$ for $\mathrm{rCP}<$ $200 \mathrm{pmol} / \mathrm{l} \mathrm{vs} \geq 200 \mathrm{pmol} / \mathrm{l}$

with those with $\mathrm{rCP} \geq 200 \mathrm{pmol} / \mathrm{l}$ (Fig. 2). The mean (95\% CI) rate of occurrence of symptoms (Clarke question 5) in low- vs high-C-peptide participants was $3.5(2.9,4.2)$ vs $1.8(1.6,2.0)$ episodes per person per month $(p<0.001)$. The mean rate without symptoms (Clarke question 6$)$ was $1.4(1.0,1.8)$ vs $0.69(0.58,0.81)$ episodes per person per month $(p<0.001)$ in the low- vs high-C-peptide group. Severe hypoglycaemia resulting in unconsciousness or seizures (Clarke question 4) was more common in those with low C-peptide (OR 5.0 [95\% CI $2.0,12.7])$ but the frequency of episodes needing external help (Clarke question 3 ) was not different $(p=0.5)$. ORs and rate ratios for self-reported hypoglycaemia (Clarke questions 3-6), by C-peptide status, are given in ESM Table 4, without and with adjustment for prandial insulin use, age, sex and $\mathrm{HbA}_{1 \mathrm{c}}$. Results were not substantially altered by adjusting for these covariates.

Questionnaire-defined hypoglycaemia unawareness (Clarke score $\geq 4$ ) occurred in $11.4 \%$ and $5.0 \%$ of those with low and high C-peptide, respectively; the difference was statistically significant only in adjusted analysis (unadjusted $p=0.17$, adjusted $p=0.005)($ ESM Table 4$)$.

The relationship between self-reported hypoglycaemia and $\mathrm{C}$-peptide is similar in type $\mathbf{1}$ and type $\mathbf{2}$ diabetes $\mathrm{In}$ participants with type 1 diabetes, $\mathrm{rCP}<200 \mathrm{pmol} / 1$ was also associated with an approximate doubling of rate of selfreported hypoglycaemia in the previous month with or without symptoms: mean $(95 \% \mathrm{CI})$ rate with symptoms (Clarke question 5) (low vs high C-peptide) $6.3(6.0,6.7)$ vs $3.0(2.4,3.7)$ episodes per person per month $(p<0.001)$; without symptoms (question 6) $1.7(1.5,1.9)$ vs $0.6(0.36$,
$0.98)$ episodes per person per month $(p<0.001)$. The difference in hypoglycaemia unawareness (Clarke score $\geq 4$ ) was not statistically different between C-peptide groups $(11.7 \%$ [95\% CI 7.4 17.4] and 3.3\% [0, 17.2] for those with C-peptide $<200 \mathrm{pmol} / 1$ and $\geq 200 \mathrm{pmol} / \mathrm{l}$, respectively, $p=0.2$ ). Results were similar after adjustment for clinical features and prandial insulin (ESM Table 4).

Thirteen per cent of patients with insulin-treated type 2 diabetes have severe insulin deficiency, even when defined by more strict criteria When using strict criteria for type 2 diabetes (clinician diagnosis of type 2 diabetes, age at diagnosis $\geq 35$ years and insulin initiation $\geq 2$ years from diagnosis, $n=203$ ), $13 \%$ (95\% CI $8.5,18$ ) of individuals meeting these criteria had C-peptide $<200 \mathrm{pmol} / \mathrm{l}$. When restricting analysis to this cohort, results were similar, with higher rates of hypoglycaemia in those with low vs high Cpeptide (Clarke question 5, 3.0 vs 1.9 episodes per person per month $[p<0.001]$; Clarke question $6,1.6$ vs 0.5 episodes per person per month $[p<0.001])$. Results were similar for participants meeting strict criteria for type 1 diabetes $(n=188)$, of whom $12 \%$ had $\mathrm{rCP} \geq 200 \mathrm{pmol} / \mathrm{l}$ (Clarke question 5, $6.1 \mathrm{vs}$ 3.6 episodes per person per month $[p<0.001]$; Clarke question $6,1.8$ vs 0.7 episodes per person per month $[p<0.001]$ ).

Hypoglycaemia rates in type 1 and type 2 diabetes with low insulin secretion are broadly similar after accounting for clinical features and insulin type In unadjusted analysis, type 1 diabetes with $\mathrm{C}$-peptide $<200 \mathrm{pmol} / \mathrm{l}$ was associated with a 1.7 times higher rate of hypoglycaemia than the rate reported by participants with type 2 diabetes and C-peptide $<200 \mathrm{pmol} / \mathrm{l}$ : rate ratio for episodes of hypoglycaemia $<3.5 \mathrm{mmol} / 1$ in the previous month in those with $\mathrm{rCP}<200 \mathrm{pmol} / 1$ for type 1 vs type 2 diabetes (Clarke questions 5 and 6 combined) was 1.66 (95\% CI $1.39,1.97)(p<0.001)$. However, after adjustment for prandial insulin use, $\mathrm{HbA}_{1 \mathrm{c}}$, sex and age this difference was modest and did not reach statistical significance (rate ratio 1.18 [0.96, 1.45], $p=0.12$ ).

\section{Discussion}

Our results demonstrate that patients with insulin-treated type 2 diabetes but low C-peptide levels have markedly increased incidence of hypoglycaemia in comparison to those with retained C-peptide, whether measured by CGM or selfreported. On CGM, glycaemic variability (when defined by $\mathrm{SD}$, the most robust measure [19,23-25]), frequency and duration of hypoglycaemia were markedly increased in those with severe insulin deficiency. More significant daytime hypoglycaemia $(<3 \mathrm{mmol} / \mathrm{l}$, [26]) was entirely confined to these participants. These differences occurred despite similar 
glycaemic control in those with and without preserved endogenous insulin secretion. Severe insulin deficiency was not uncommon in participants with insulin-treated type 2 diabetes in our cohort, occurring in $13 \%$ of participants even when strict clinical criteria for classification were applied. While many of these participants may have diabetes of autoimmune aetiology, this was not clinically recognised or apparent, with low-C-peptide participants having late-onset diabetes, raised BMI and time from diagnosis to insulin treatment of several years.

\section{Comparison with other studies}

Our findings of a strong association between C-peptide and hypoglycaemia are consistent with previous findings in type 1 diabetes using self-reported hypoglycaemia $[1,3,9,10,19]$ and CGM studies in type 1 diabetes demonstrating higher SD or $\mathrm{CV}$ ( $\mathrm{SD} /$ glucose), defined glucose variability and hypoglycaemia in individuals with lower C-peptide, including after islet transplant [27-29]. In these studies, C-peptide was measured using a mixed meal tolerance test, which is not suitable for routine use in clinical practice. One study examined the correlation between fasting C-peptide and glucose variability (CGM SD) and found inverse associations in both type 1 diabetes and insulin-treated type 2 diabetes, although hypoglycaemia was not examined [30].

The relationship between C-peptide levels and frequency of hypoglycaemia in those with a clinical diagnosis of type 2 diabetes is less widely recognised. The frequency of hypoglycaemia in type 2 diabetes is known to be associated with diabetes duration [31], and is markedly higher in individuals treated with insulin for a long period than in those in the initial stages of treatment [32]. It has also recently been shown that individuals with type 2 diabetes who were unable to achieve the ACCORD study's treatment target of $\mathrm{HbA}_{1 \mathrm{c}}<6.0 \%$ (42 $\left.\mathrm{mmol} / \mathrm{mol}\right)$ due to severe hypoglycaemia had lower C-peptide, with an OR of 23 for low C-peptide (baseline fasting C-peptide $<0.15 \mathrm{nmol} / \mathrm{l}$ ) [33].

While the potential utility of $\mathrm{rCP}$ as a biomarker for hypoglycaemia in individuals with diabetes has not been previously examined, previous research has shown that this test is highly correlated with mixed-meal-test-measured Cpeptide [11] and has similar or superior utility to glucagonstimulated C-peptide assessment for differentiating between type 1 and type 2 diabetes [34].

\section{Strengths and limitations}

This is to our knowledge the first study to examine the relationship between C-peptide and CGM-assessed hypoglycaemia in type 2 diabetes and the first to assess the potential utility of rCP for stratification of hypoglycaemia risk. This is an inexpensive test that can be measured at the point of clinical contact and could therefore easily be incorporated into clinical practice. Our additional study in a larger cohort using self-reported hypoglycaemia as an outcome strengthens our findings. We have assessed an older adult population in our study, an age group wherein hypoglycaemia is often not recognised, and consequences are more severe [35] and where risk biomarker-based stratification would therefore be particularly helpful.

A weakness of our study is that C-peptide assessment in our replication study was in the most part performed on routine non-fasting plasma-EDTA samples received by our laboratory, therefore did not assess concurrent glucose or timing of samples in relation to meals. We have previously shown concurrent hypoglycaemia may result in reduced $\mathrm{rCP}$ levels and recommended that when assessing $\mathrm{rCP}$, concurrent hypoglycaemia is excluded and a sample taken $1-5 \mathrm{~h}$ post meal [11]. An additional weakness is that we cannot fully account for potential confounders which may alter the relationship between C-peptide and hypoglycaemia. In our CGM study, although most clinical characteristics were very similar between groups, prandial insulin use was more common in those with low C-peptide. This may reflect a causal association (those with low C-peptide and high glucose variability are likely to need prandial insulin for glycaemic control), although insulin regimen may directly influence hypoglycaemia [20, 21]. Importantly, adjusting for insulin regime in our analysis did not alter our findings. In our questionnaire study, rates of self-reported hypoglycaemia were likely to be very dependent on rates of self-monitoring of blood glucose levels, which was not assessed.

\section{Clinical implications}

Our results suggest that an rCP sample can identify patients with insulin-treated type 2 diabetes who have a markedly increased risk of hypoglycaemia. These patients could not be identified by their clinical characteristics and only $59 \%$ would be identified by islet autoantibody testing, supporting the potential utility of rCP testing, which is practical, stable and inexpensive and therefore ideal for clinical use.

Identifying patients with insulin-treated type 2 diabetes at high risk of hypoglycaemia would be clinically helpful in guiding management (e.g. in setting appropriate glycaemic targets and levels of glucose monitoring) and would potentially allow consideration of treatment strategies for high glucose variability traditionally used in type 1 diabetes, such as carbohydrate counting and use of subcutaneous insulin pumps. An additional area where a robust, easily measurable biomarker for hypoglycaemia risk would be useful is in stratification of hypoglycaemia risk in relation to driving. Our CGM data showing no daytime episodes $\leq 3 \mathrm{mmol} / \mathrm{mol}$ in those with high $\mathrm{rCP}$ and an OR of 9.5 for self-reported severe hypoglycaemia (unconscious or fit, adjusted analysis) 
in the last year in those with low $\mathrm{rCP}$ are of interest in this regard and warrant further investigation.

\section{Unanswered questions and future research}

In this study, we used a previously defined threshold for hypoglycaemia risk based on previous studies in type 1 diabetes, and in our CGM cohort we excluded participants with C-peptide between 200 and $600 \mathrm{pmol} / \mathrm{l}$ (23\% and 7\% of participants in our type 2 diabetes and type 1 diabetes questionnaire cohorts, respectively). The relationship between C-peptide and glucose variability in previous literature is continuous but non-linear, with a very strong association at low but not high C-peptide levels [28, 29, 36]. This is similar to the relationship observed with self-reported hypoglycaemia in our cohort (ESM Fig. 1). Further studies are needed to define optimal clinical cut-offs in obese populations with type 2 diabetes or alternatively to examine more complex approaches to risk prediction which might account for Cpeptide as a continuous variable alongside other predictive features. Larger studies are needed to assess $\mathrm{rCP}$ against robust clinically important hypoglycaemia outcomes such as severe hypoglycaemia and to formally assess effectiveness and cost effectiveness of biomarker-based stratification of management. While it is likely that our results will be equally applicable to individuals diagnosed with type 1 diabetes, we did not directly assess this in our CGM study, which is thus an area of future work.

\section{Conclusions}

Low $\mathrm{rCP}$ is associated with increased glucose variability and hypoglycaemia in patients with insulin-treated type 2 diabetes and represents a practical, stable and inexpensive biomarker for assessment of hypoglycaemia risk.

\begin{abstract}
Acknowledgements The authors thank staff of the National Institute for Health Research Exeter Clinical Research Facility (University of Exeter and Royal Devon and Exeter Hospital) and the Blood Sciences Department, Royal Devon and Exeter Hospital for assistance with conducting the study. In particular, T. Libretto, R. Bolt, D. McGill, B. Knight, R. Kelland and A. Tregarthen (National Institute for Health Research Exeter Clinical Research Facility) are thanked for help with data collection. We thank A. Hattersley (University of Exeter) for helpful discussion.
\end{abstract}

Data availability Data can be obtained by contacting AGJ or SVH directly.

Funding This study was funded by the Northcott Devon Foundation and the NIHR Exeter Clinical Research Facility. BMS, AVH, and BAK are core staff members of the National Institute for Health Research Exeter Clinical Research Facility. WDS is in receipt of an NIHRHEFCE 'New Blood' Senior lectureship, PC is Senior Lecturer at
King's College London, TJM is an NIHR CSO Fellow and AGJ is an NIHR Clinician Scientist. The views expressed are those of the authors and not necessarily those of the NHS, the NIHR or the Department of Health.

Duality of interest PC has received travel support and honoraria and participated in advisory boards for manufacturers of CGM devices (Medtronic Ltd, Dexcom Ltd, Abbott Diabetes Care). All other authors declare that there is no duality of interest associated with their contribution to this manuscript.

Contribution statement SVH, BAK and AGJ designed the study with assistance from TJM, PC and WDS. SVH, BAK and AVH researched the data. SVH, AGJ and BMS analysed the data. SVH and AGJ drafted the manuscript. BAK, AVH, BMS, PC, WDS, and TJM provided helpful discussion and reviewed/edited the manuscript. All authors approved the final manuscript. AGJ is the guarantor of this work and, as such, had full access to all the data in the study and takes responsibility for the integrity of the data and the accuracy of the data analysis.

Open Access This article is distributed under the terms of the Creative Commons Attribution 4.0 International License (http:// creativecommons.org/licenses/by/4.0/), which permits unrestricted use, distribution, and reproduction in any medium, provided you give appropriate credit to the original author(s) and the source, provide a link to the Creative Commons license, and indicate if changes were made.

\section{References}

1. The Diabetes Control and Complications Trial Research Group (1991) Epidemiology of severe hypoglycemia in the Diabetes Control and Complications Trial. Am J Med 90:450-459

2. The Diabetes Control and Complications Trial Research Group (1997) Hypoglycemia in the Diabetes Control and Complications Trial. Diabetes 46:271-286

3. Steffes MW, Sibley S, Jackson M, Thomas W (2003) $\beta$-cell function and the development of diabetes-related complications in the Diabetes Control and Complications Trial. Diabetes Care 26:832-836

4. Greven W, Beulens J, Biesma D, Faiz S, De Valk H (2010) Glycemic variability in inadequately controlled type 1 diabetes and type 2 diabetes on intensive insulin therapy: a cross-sectional, observational study. Diabetes Technol Ther 12:695-699

5. NICE (2015) Type 1 diabetes in adults: diagnosis and management. Available from https://www.nice.org.uk/guidance/ng17. [NICE Guidelines NG17] Accessed 6 Mar 2017

6. Jones AG, Hattersley AT (2013) The clinical utility of C-peptide measurement in the care of patients with diabetes. Diabet Med 30: 803-817

7. Wang L, Lovejoy NF, Faustman DL (2012) Persistence of prolonged C-peptide production in type 1 diabetes as measured with an ultrasensitive C-peptide assay. Diabetes Care 35:465-470

8. Oram RA, McDonald TJ, Shields BM et al (2015) Most people with long-duration type 1 diabetes in a large population-based study are insulin microsecretors. Diabetes Care 38:323-328

9. Kuhtreiber WM, Washer SLL, Hsu E et al (2015) Low levels of Cpeptide have clinical significance for established Type 1 diabetes. Diabet Med 32:1346-1353

10. Lachin JM, McGee P, Palmer JP, for the DCCT/EDIC Research Group (2014) Impact of C-peptide preservation on metabolic and clinical outcomes in the Diabetes Control and Complications Trial. Diabetes 63:739-748

11. Hope SV, Knight BA, Shields BM, Hattersley AT, McDonald TJ, Jones AG (2016) Random non-fasting C-peptide: bringing robust 
assessment of endogenous insulin secretion to the clinic. Diabet Med 33:1554-1558

12. McDonald TJ, Perry MH, Peake RWA et al (2012) EDTA improves stability of whole blood C-peptide and insulin to over 24 hours at room temperature. PLoS One 7:e42084

13. Hope SV, Jones AG, Goodchild E et al (2013) Urinary C-peptide creatinine ratio detects absolute insulin deficiency in Type 2 diabetes. Diabet Med 30:1342-1348

14. Jones AG, McDonald TJ, Shields BM et al (2016) Markers of $\beta$ cell failure predict poor glycemic response to GLP-1 receptor agonist therapy in type 2 diabetes. Diabetes Care 39:250-257

15. Hope SV, Wienand-Barnett S, Shepherd M et al (2016) Practical classification guidelines for diabetes in patients treated with insulin: a cross-sectional study of the accuracy of diabetes diagnosis. Br J Gen Pract 66:e315-e322

16. Gottsater A, Landin-Olsson M, Fernlund P, Lernmark A, Sundkvist $\mathrm{G}$ (1993) $\beta$-Cell function in relation to islet cell antibodies during the first $3 \mathrm{yr}$ after clinical diagnosis of diabetes in type II diabetic patients. Diabetes Care 16:902-910

17. Clarke WL, Cox DJ, Gonder-Frederick LA, Julian D, Schlundt D, Polonsky W (1995) Reduced awareness of hypoglycemia in adults with IDDM: a prospective study of hypoglycemic frequency and associated symptoms. Diabetes Care 18:517-522

18. Choudhary P, Geddes J, Freeman JV, Emery CJ, Heller SR, Frier BM (2010) Frequency of biochemical hypoglycaemia in adults with Type 1 diabetes with and without impaired awareness of hypoglycaemia: no identifiable differences using continuous glucose monitoring. Diabet Med 27:666-672

19. Hill N, Oliver N, Choudhary P, Levy J, Hindmarsh P, Matthews D (2011) Normal reference range for mean tissue glucose and glycemic variability derived from continuous glucose monitoring for subjects without diabetes in different ethnic groups. Diabetes Technol Ther 13:921-928

20. Riddle MC, Rosenstock J, Vlajnic A, Gao L (2014) Randomized, 1year comparison of three ways to initiate and advance insulin for type 2 diabetes: twice-daily premixed insulin versus basal insulin with either basal-plus one prandial insulin or basal-bolus up to three prandial injections. Diabetes Obes Metab 16:396-402

21. Holman R, Farmer A, Davies M et al (2009) Three-year efficacy of complex insulin regimens in type 2 diabetes. N Engl J Med 361: $1736-1747$

22. NICE (2016) Integrated sensor-augmented pump therapy systems for managing blood glucose levels in type 1 diabetes (the MiniMed Paradigm Veo system and the Vibe and G4 PLATINUM CGM system). Diagnostics Guidance [DG21]. Available from https:// www.nice.org.uk/guidance/dg21. Accessed 24 Mar 2017

23. Rodbard D (2009) Interpretation of continuous glucose monitoring data: glycemic variability and quality of glycemic control. Diabetes Technol Ther 11:S55-S67
24. Rodbard D (2009) New and improved methods to characterize glycemic variability using continuous glucose monitoring. Diabetes Technol Ther 11:551-565

25. Gribovschi M, Țigan Ș, Hancu N (2013) Glycemic variability and type 2 diabetes mellitus. Appl Med Inform 32:53-60

26. ADA/EASD (2017) Glucose concentrations of less than $3.0 \mathrm{mmol} / \mathrm{l}$ $(54 \mathrm{mg} / \mathrm{dl})$ should be reported in clinical trials: a joint position statement of the American Diabetes Association and the European Association for the Study of Diabetes. Diabetologia 60:3-6

27. Buckingham B, Cheng P, Beck RW et al (2015) CGM-measured glucose values have a strong correlation with $\mathrm{C}$-peptide, $\mathrm{HbA1c}$ and IDAAC, but do poorly in predicting C-peptide levels in the two years following onset of diabetes. Diabetologia 58:1167-1174

28. Pinckney A, Rigby MR, Keyes-Elstein L, Soppe CL, Nepom GT, Ehlers MR (2016) Correlation among hypoglycemia, glycemic variability, and C-peptide preservation after Alefacept therapy in patients with type 1 diabetes mellitus: analysis of data from the immune tolerance network T1DAL trial. Clin Ther 38: 1327-1339

29. Brooks AM, Oram R, Home P, Steen N, Shaw JA (2015) Demonstration of an intrinsic relationship between endogenous C-peptide concentration and determinants of glycemic control in type 1 diabetes following islet transplantation. Diabetes Care 38: $105-112$

30. Jin SM, Kim TH, Bae JC et al (2014) Clinical factors associated with absolute and relative measures of glycemic variability determined by continuous glucose monitoring: an analysis of 480 subjects. Diabetes Res Clin Pract 104:266-272

31. Henderson JN, Allen KV, Deary IJ, Frier BM (2003) Hypoglycaemia in insulin-treated Type 2 diabetes: frequency, symptoms and impaired awareness. Diabet Med 20:1016-1021

32. Hermansen K, Kipnes M, Luo E, Fanurik D, Khatami H, Stein P (2007) Efficacy and safety of the dipeptidyl peptidase-4 inhibitor, sitagliptin, in patients with type 2 diabetes mellitus inadequately controlled on glimepiride alone or on glimepiride and metformin. Diabetes Obes Metab 9:733-745

33. Chow L, Chen H, Miller M, Marcovina S, Seaquist E (2015) Biomarkers related to severe hypoglycaemia and lack of good glycaemic control in ACCORD. Diabetologia 58:1160-1166

34. Berger B, Stenstrom G, Sundkvist G (2000) Random C-peptide in the classification of diabetes. Scand J Clin Lab Invest 60:687-693

35. Hope S, Strain W (2013) Hypoglycemia in the elderly. Diabetic Hypoglycemia 6:3-10

36. Jones A, Besser R, Shields B et al (2012) Assessment of endogenous insulin secretion in insulin treated diabetes predicts postprandial glucose and treatment response to prandial insulin. BMC Endocr Disord 12:6 